\title{
The Transmission of German Monetary Policy in the Pre-Euro Period*
}

\author{
by \\ Helmut Lütkepohl \\ Institut für Statistik und Ökonometrie, Wirtschaftswissenschaftliche Fakultät, \\ Humboldt-Universität, Spandauer Str. 1, 10178 Berlin, GERMANY \\ and \\ Jürgen Wolters \\ Institut für Statistik und Ökonometrie, Fachbereich Wirtschaftswissenschaft, Freie \\ Universität and DIW Berlin, Boltzmannstr. 20, 14195 Berlin, GERMANY
}

\begin{abstract}
A small macroeconomic model is constructed to study the transmission of the monetary policy conducted by the Deutsche Bundesbank (DBB) since the middle of the 1970s. For this purpose quarterly, seasonally unadjusted data for the period from 1975 to 1998 are used, that is, the period until the introduction of the Euro is considered. A vector error correction model is constructed for the German monetary sector based on M3, GNP, an inflation rate, a long-term interest rate and a short-term rate which represents the policy variable of the DBB. Moreover, import price inflation is included as an exogenous variable to capture foreign effects. An impulse response analysis highlights the effects of changes in the short-term interest rate and shows the interaction of the main variables of the monetary sector.
\end{abstract}

Key Words: Cointegration analysis, impulse response analysis, monetary policy, money demand, structural vector error correction model

JEL classification: C32, E52, E41

\footnotetext{
${ }^{*}$ We thank Alexander Benkwitz for helping with the computations. Financial support was provided by the Deutsche Forschungsgemeinschaft, Sonderforschungsbereich 373, and the European Commission under the Training and Mobility of Researchers Programme (contract No. ERBFMRXCT980213).
} 
Starting in 1975 the Deutsche Bundesbank (DBB) has used a money growth target to control inflation in Germany (see, e.g., Issing (1997)). A number of attempts have been made to model the transmission process of this policy. Monetary systems for Germany were analyzed, for instance, by Hansen \& Kim (1996), Juselius (1996, 1998), Hubrich (1998, 2001), Deutsche Bundesbank (1997), Lütkepohl \& Wolters (1998) (henceforth LW), Benkwitz, Lütkepohl \& Wolters (2001) and Brüggemann (2001). All these studies consider small dynamic models focussed on M3 as the measure for the money stock and they examine the dynamic interaction in the monetary sector. In none of these studies the impact of changes in a policy variable is analyzed for the full period of monetary targeting by the DBB, however. A brief account of important features of some of the models considered is given in LW.

In this study we shall use the cointegration toolkit and construct a vector error correction model (VECM) for the monetary sector of the economy which also includes the overnight money market rate $(r)$ as instrument variable. Our objective is to construct a model with a small number of variables and also impose as many restrictions on the short-run dynamics as possible. The analysis is based on seasonally unadjusted quarterly data. We examine the complete period of monetary targeting by the DBB from 1975 to 1998 and thereby we hope to contribute to the understanding of an important historical period of German monetary policy. Notice that the DBB announced the first money growth target for 1975 which marks a change in its policy (see Deutsche Bundesbank (1998) for a detailed account of the DBB's policy). With the introduction of the Euro on January 1, 1999 responsibility for German monetary policy was no longer with the DBB but was transferred to the European Central Bank (ECB). Because the latter institution uses a money growth target as one pillar of its monetary policy, the implications of this kind of policy are presently of central importance for understanding the transmission mechanism in the Euro area.

Our model is in some respects similar to the one of LW. Endogenous variables are the money stock measured by M3, Gross National Product (GNP) to represent the transactions volume, the inflation rate based on the GNP deflator and the average bond rate (' $\mathrm{Um}$ laufsrendite') as a long-term interest rate. The policy variable $r$ is treated as exogenous and foreign factors are captured by the import price inflation which is also an unmodeled variable in the system. The model is based on the typical IS-LM-AS scheme. It is centered around 
a money demand relation which represents the link to the real sector of the economy. The model is structural in the sense that it includes instantaneous relations between endogenous variables in the money market whereas the IS curve and the supply relation are modeled in reduced form.

Because our sample period covers German reunification in 1990, a shift in the variables and possibly the relations between them has to be taken care of in the model. We do so by including appropriate dummy variables. Due to the extended sample period relative to LW and as a consequence of the adjustment processes between East and West Germany, the modeling of the shift becomes even simpler than in LW. The major conceptual difference to the study of LW results, however, from including the overnight rate and, hence, an instrument variable of the $\mathrm{DBB}$ instead of the own rate of M3. In fact, LW include an interest rate spread variable only to account for opportunity costs for holding money. Instead we include a long-term and a short-term interest rate separately. Thereby we are able to examine the impact of the monetary policy of the DBB directly. Moreover, more refined approaches to handle structural breaks in integrated and cointegrated time series are employed.

The actual interactions between the variables are investigated with an impulse response analysis. In contrast to LW who do not report confidence intervals for the impulse responses, we follow Benkwitz, Lütkepohl \& Wolters (2001) and use a bootstrap method for assessing the sampling variability of the impulse responses. Our present results indicate that the short-term interest rate was an effective policy instrument and they confirm the channels of the monetary policy assumed by the DBB. In particular, it is found that monetary shocks lead to rising inflation.

The structure of our study is as follows. The data and some important aspects of the economic framework are discussed in the following section. Unit root and cointegration analyses of the variables involved are performed in Sec. 3 and the empirical model is presented and discussed in Sec. 4. An analysis of the dynamic relations between the variables based on impulse responses is considered in Sec. 5. Finally, Sec. 6 concludes. 


\section{Data and Modeling Background}

The general model used in the following analysis is a VECM of the form

$$
\Gamma_{0} \Delta z_{t}=\alpha \beta^{\prime} z_{t-1}+\Gamma_{1} \Delta z_{t-1}+\cdots+\Gamma_{n} \Delta z_{t-n}+\Phi x_{t}+\Xi D_{t}+u_{t}
$$

where the vector $z_{t}$ contains the endogenous variables, $\Delta$ is the differencing operator so that $\Delta z_{t}=z_{t}-z_{t-1}, x_{t}$ is a vector of exogenous or unmodeled variables, $D_{t}$ represents the deterministic terms and $u_{t}$ is the error vector which is assumed to be white noise, that is, $u_{t}$ is supposed to be serially uncorrelated with zero mean and constant nonsingular covariance matrix $\Sigma_{u}$. The $\Gamma_{i}$ matrices are structural coefficient matrices because $\Gamma_{0}$ is not assumed to be an identity matrix. The first term on the right-hand side of the system (2.1) is the error correction term with $\beta^{\prime} z_{t-1}$ representing the cointegration relations. Furthermore, $\alpha$ is the loading matrix which contains the weights of the cointegration relations in the equations of the system. We will use the general model (2.1) as a framework for constructing a quarterly model for the monetary sector of the German economy.

As in LW, we regard the money demand relation as the center piece of our model and choose the endogenous variables accordingly. For monetary targeting to be a successful strategy, money growth must be controllable by the central bank and there has to be a strong relation between money and inflation. A necessary condition for these requirements is a stable money demand function. The relevant money variable is M3 because the growth rate of this variable was used as an intermediate target by the DBB since 1988. Its logarithm will be denoted by $m_{t}$. Money demand was found to depend on the transactions volume and opportunity cost variables. The former variable is approximated by GNP whereas the inflation rate and an interest rate are candidates for representing opportunity costs. The interpretation of the inflation rate in a money demand relation is not straightforward because it may capture opportunity costs of holding real assets and also relates to the portfolio adjustment process. More precisely, it measures whether the asset adjustment is in real or nominal terms (see Wolters \& Lütkepohl (1997)). Because LW found a log-linear relation to work well, we denote by $y_{t}$ the $\log$ of real GNP, $p_{t}$ is the log of the GNP deflator so that $\Delta p_{t}$ is the (quarterly) inflation rate and $R_{t}$ represents a long-term interest rate for which we use an average bond rate. Thus, the long-run money demand relation we have in mind is of the 
following form

$$
(m-p)_{t}=\beta_{1} y_{t}+\beta_{2} \Delta p_{t}+\beta_{3} R_{t}+\text { error }_{t}
$$

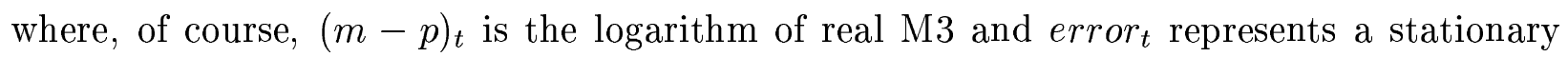
error term. This relation is similar but not identical to the one found to work well in LW and Wolters, Teräsvirta \& Lütkepohl (1998). The difference is that we use the long-term interest rate $R_{t}$ instead of an interest rate spread consisting of the difference between $R_{t}$ and the own interest rate of M3. Including the interest rate spread as an opportunity cost variable is quite natural. On the other hand, we intend to study the DBB policy and, hence, we include the overnight rate as instrument variable of the DBB. Therefore we delete the own rate of $\mathrm{M} 3$ which is also a short-term interest rate. In summary, our minimal set of endogenous variables in the $\operatorname{VECM}(2.1)$ is $z_{t}=\left[(m-p)_{t}, y_{t}, \Delta p_{t}, R_{t}\right]^{\prime}$. A more detailed discussion of the money demand relation may be found in LW.

There should be at least one cointegration relation in our system which could be identified as a money demand equation. Moreover, there is a second possible cointegration relation in our set of endogenous variables. For instance, Hubrich (2001) finds that the real longterm interest rate is stationary ('Fisher effect') for her sample period. Thus, because we are considering a quarterly model and, hence, $4 \Delta p_{t}$ is a proxi for the annual inflation rate, $R_{t}-$ $4 \Delta p_{t}$ may be another cointegration relation in our system. The integration and cointegration properties of our variables will be analyzed in detail in the next section.

As mentioned earlier, the overnight rate $r_{t}$ is used as the instrument variable of the DBB. It is treated as an unmodeled variable although it is, of course, to some extent endogenously determined in the system. Note that the DBB has decided on interest rate changes on the basis of the economic conditions and, in particular, taking into account the growth rate of the money stock. Still, it turns out that conditioning on this variable is justified in the framework of our analysis because lags of the other variables turned out to be not significant in an equation for $r_{t}$. We will come back to this issue in Sec. 4.

The exchange rate is another potentially important variable for modeling the transmission mechanism of monetary policy because Germany is an open economy (see also Issing \& Tödter (1995), Hansen \& Kim (1996) and Deutsche Bundesbank (1997)). We use the logarithm of an import price index $p m_{t}$ as an exogenous variable to capture the effects of the exchange rate. Because $p m_{t}$ is found to be potentially $I(1)$ in the unit root analysis in 
the next section, we actually include $\Delta p m_{t}$, the inflation rate of import prices, in the set of exogenous, unmodeled variables. Thus our vector $x_{t}$ consists of the variables $r_{t}$ and $\Delta p m_{t}$ and/or their lags.

- Figure 1 about here -

For all the endogenous and exogenous variables we use quarterly, seasonally unadjusted data for the period 1975(1) to 1998(4). In addition, the last value of 1974 may be used when differences are considered. The precise data sources are given in the Appendix and the series are plotted in Figure 1. Our sample period covers the full period of monetary targeting by the DBB from the middle of the 1970s to the time when the German mark became a subcurrency of the Euro. This contrasts with previous studies where only subperiods are covered (see LW for a brief review of previous studies). In particular, we also include the German monetary unification (GMU) on 1 July 1990 in our sample period. These and some other important events require special precautions in our model. We will see in Sec. 4 that the effects of these events can be captured by a small set of dummies which will be included in the term $D_{t}$ in our general model (2.1). In particular, we will use the three impulse dummies $I 90 q 3_{t}, I 92 q 4_{t}$, and $I 94 q 4_{t}$ which are one in 1990(3), 1992(4), and 1994(4), respectively, and zero elsewhere. Clearly, $I 90 q 3_{t}$ is needed to account for the GMU. Reasons for $I 92 q 4_{t}$ to be important in our model are the crisis in the European exchange rate mechanism (ERM) in September 1992 and the reintroduction of a withholding tax on interest income in Germany, effective January 1, 1993. Finally, $I 94 q 4_{t}$ captures unusually slow and even negative growth of the money stock due to an enormous substitution into short-term interest bearing assets not included in M3. Also summarized in the deterministic term $D_{t}$ are seasonal dummy variables and a constant.

Because we are using quarterly data, we use a lag order of $n=4$ in the final modeling procedure in Sec. 4. This lag order is also consistent with the one used by LW. As in their study, we find that it is sufficient to capture the dynamics of the model. As a result, the sample used for the actual estimation of the final model begins in 1976(1) so that we have 92 observations for estimation and inference. The values from the year 1975 are used as presample values only. In the next section we examine the unit root and cointegration properties of our system in some detail because a proper specification of the error correction term is important for our modeling strategy. 


\section{Unit Root and Cointegration Analysis}

We begin by investigating the order of integration of the variables of interest. The results of unit root tests are reported in Table 1. The usual augmented Dickey-Fuller (ADF) tests are performed for most of the series. The money and income series receive a special treatment because they have a level shift (see Figure 1). For these series we use the tests proposed by Lanne, Lütkepohl \& Saikkonen (2001) (abbreviated as LLS in Table 1) because they were shown to perform better than other alternatives such as the one proposed by Perron (1989, 1990) that allow for a level shift (see Lanne \& Lütkepohl (2001)). These tests proceed by estimating the deterministic terms in a first step by a GLS procedure and then subtracting the estimated deterministic term including the level shift. In a second step, an ADF type test is applied to the adjusted series. In all the tests the specification of the deterministic term and the lag order are important and may determine the test result. Therefore, in some cases we report tests for different sets of deterministic terms and lag orders. The latter quantities are chosen by the Akaike (AIC) and Hannan-Quinn (HQ) criteria (see, e.g, Lütkepohl (1991) for definitions) using a maximum lag order of ten. We also tried a number of variations which generally confirmed the results in Table 1. For example, for some series we also tried different lag orders and deterministic terms. In particular, we investigated the implications of using a more flexible shift function for the money and income series to account for the GMU shift. Our analysis confirmed that a simple shift dummy variable is sufficient here. Consequently, we use $S 90 q 3_{t}$ which is zero until the second quarter of 1990 and one from the third quarter of that year onwards. The computations were done with GAUSS programs (see JMulTi, http://ise.wiwi.hu-berlin.de/oekonometrie/).

From the results in Table 1 it can be inferred that $m-p, y, \Delta p$ and $R$ are clearly integrated of order one $(I(1))$. Furthermore, there is some evidence that the overnight rate is stationary $(I(0))$. Depending on the lag order, a unit root is rejected at a $5 \%$ or $10 \%$ level. Given that unit root tests are known to have relatively little power, such an outcome may be evidence for stationarity. The situation is not quite so clear for the import price index $\mathrm{pm}$. Looking at the graph in Figure 1, it makes sense to include a linear time trend in the test regression. If that is done, a unit root cannot be rejected at the $10 \%$ level of significance. If the trend is not included, however, a unit root is rejected at the $10 \%$ level. In the following analysis we treat $p m$ as an $I(1)$ variable and include lags of first differences as conditioning 
Table 1: Unit Root Tests for Sample Period 1975(1) to 1998(4)

\begin{tabular}{|c|c|c|c|c|}
\hline variable & $\begin{array}{l}\text { deterministic } \\
\text { terms }\end{array}$ & $\begin{array}{l}\text { lag } \\
\text { order }\end{array}$ & test & $\begin{array}{l}\text { value of } \\
\text { test stat. }\end{array}$ \\
\hline$(m-p)_{t}$ & $c, t, s d, S 90 q 3$ & $n(\mathrm{AIC})=n(\mathrm{HQ})=0$ & LLS & -1.36 \\
\hline$y_{t}$ & $c, t, s d, S 90 q 3$ & $n(\mathrm{AIC})=n(\mathrm{HQ})=1$ & LLS & -1.92 \\
\hline \multirow[t]{4}{*}{$\Delta p_{t}$} & \multirow[t]{2}{*}{$c, t, s d$} & $n(\mathrm{AIC})=5$ & $\mathrm{ADF}$ & -2.46 \\
\hline & & $n(\mathrm{HQ})=3$ & $\mathrm{ADF}$ & -2.72 \\
\hline & \multirow[t]{2}{*}{$c, s d$} & $n(\mathrm{AIC})=5$ & $\mathrm{ADF}$ & -1.83 \\
\hline & & $n(\mathrm{HQ})=3$ & $\mathrm{ADF}$ & -2.17 \\
\hline$R_{t}$ & $c$ & $n(\mathrm{AIC})=n(\mathrm{HQ})=1$ & $\mathrm{ADF}$ & -1.44 \\
\hline \multirow[t]{2}{*}{$r_{t}$} & \multirow[t]{2}{*}{$c$} & $n(\mathrm{AIC})=5$ & $\mathrm{ADF}$ & $-2.94^{*}$ \\
\hline & & $n(\mathrm{HQ})=3$ & $\mathrm{ADF}$ & $-2.76^{(*)}$ \\
\hline \multirow[t]{2}{*}{$p m_{t}$} & $c, t, s d$ & $n(\mathrm{AIC})=n(\mathrm{HQ})=2$ & $\mathrm{ADF}$ & -2.14 \\
\hline & $c, s d$ & $n(\mathrm{AIC})=n(\mathrm{HQ})=2$ & $\mathrm{ADF}$ & $-2.59^{(*)}$ \\
\hline$\Delta(m-p)_{t}$ & $c, s d, I 90 q 3$ & $n(\mathrm{AIC})=n(\mathrm{HQ})=0$ & LLS & $-7.78^{* *}$ \\
\hline$\Delta y_{t}$ & $c, s d, I 90 q 3$ & $n(\mathrm{AIC})=n(\mathrm{HQ})=0$ & LLS & $-12.31^{* *}$ \\
\hline \multirow[t]{2}{*}{$\Delta^{2} p_{t}$} & \multirow[t]{2}{*}{$c, s d$} & $n(\mathrm{AIC})=6$ & $\mathrm{ADF}$ & $-4.98^{* *}$ \\
\hline & & $n(\mathrm{HQ})=2$ & $\mathrm{ADF}$ & $-13.21^{* *}$ \\
\hline$\Delta R_{t}$ & & $n(\mathrm{AIC})=n(\mathrm{HQ})=0$ & $\mathrm{ADF}$ & $-8.33^{* *}$ \\
\hline \multirow[t]{2}{*}{$\Delta p m_{t}$} & \multirow[t]{2}{*}{$c, s d$} & $n(\mathrm{AIC})=1$ & $\mathrm{ADF}$ & $-4.04^{* *}$ \\
\hline & & $n(\mathrm{HQ})=0$ & $\mathrm{ADF}$ & $-6.51^{* *}$ \\
\hline$(R-4 \Delta p)_{t}$ & $c, s d$ & $n(\mathrm{AIC})=n(\mathrm{HQ})=5$ & $\mathrm{ADF}$ & $-3.42^{*}$ \\
\hline
\end{tabular}

Notes: $c$ - constant, $t$ - linear time trend, $s d$ - seasonal dummies, $S 90 q 3$ - shift dummy which is 1 from $1990(3)$ onwards, $I 90 q 3=\Delta S 90 q 3$ - impulse dummy.

$n$ (AIC) and $n$ (HQ) are the lag orders recommended by the AIC and HQ criterion, respectively, when the maximum lag order is 10.

LLS denotes the preferred test $\left(\tau_{\text {int }}^{+}\right)$proposed by Lanne, Lütkepohl \& Saikkonen (2001), where also critical values can be found. ADF denotes the augmented Dickey-Fuller test with critical values from MacKinnon (1991). Asterisks ${ }^{(*)},{ }^{*}$ and ${ }^{* *}$ indicate that the null hypothesis of a unit root can be rejected at the $10 \%, 5 \%$ and $1 \%$ levels, respectively. 
variables because this results in a well specified model. The result for the real long-term interest rate, $R^{r}=R-4 \Delta p$, which is also shown in Table 1, will be discussed later.

The cointegration properties of the endogenous $I(1)$ variables were investigated by Johansen's trace tests (Johansen (1995)) and a variant proposed by Saikkonen \& Lütkepohl (2000a, b). The latter tests will be abbreviated as S\&L tests. They are especially designed to account for structural shifts as they are present in some of our series. The general underlying model is of the form

$$
z_{t}=\mu_{0}+\mu_{1} t+\gamma_{1} d_{1 t}+\gamma_{2} d_{2 t}+\gamma_{3} d_{3 t}+\delta S 90 q 3_{t}+w_{t}
$$

where $z_{t}$ is the vector of observed variables, as before, $d_{i t}(i=1,2,3)$ are seasonal dummy variables and $S 90 q 3_{t}$ is the shift dummy variable which accounts for the GMU. The quantities $\mu_{0}, \mu_{1}, \gamma_{i}(i=1,2,3)$, and $\delta$ are parameter vectors associated with the deterministic terms. Finally $w_{t}$ is a purely stochastic term with a VECM representation

$$
\Delta w_{t}=\Pi w_{t-1}+\sum_{j=1}^{n} \Xi_{j} \Delta w_{t-j}+u_{t}
$$

which specifies the cointegration properties of the system. Writing the process in the form (3.1) and thereby separating the deterministic and stochastic terms, simplifies the choice of terms to be included in the cointegration tests discussed below. In some of the systems to be considered we do not need to include all the deterministic terms. In that case the corresponding parameter vectors are restricted to zero.

The Johansen trace tests are likelihood ratio (LR) tests based on a reduced rank regression of the corresponding VECM model for $z_{t}$. Suitable critical values depend on the deterministic terms included in the test regression. They are available in tables in Johansen (1995) for the cases where no shift dummy variable is present. If a shift dummy is included, the asymptotic distribution under the null hypothesis depends on the fraction of the sample before and after the break which requires simulation of new critical values for each specific situation. Therefore we prefer the approach of Saikkonen \& Lütkepohl (2000a, b) who propose a test which is asymptotically unaffected by shift dummies. The S\&L tests proceed by first estimating the parameters of the $w_{t}$ process from a reduced rank regression of the VECM for $z_{t}$, as in the Johansen tests. Then the deterministic terms are estimated by a feasible GLS procedure applied to (3.1) and the estimated terms are subtracted from the $z_{t}$ giving $\tilde{w}_{t}$. Finally the tests are performed on the model (3.2) replacing $w_{t}$ by $\tilde{w}_{t}$. Notice 
that the asymptotic null distributions of these tests are different from the Johansen trace tests. Critical values are tabulated in Lütkepohl \& Saikkonen (2000). In both tests, the lag order $n$ is chosen by model selection criteria. In particular we have used AIC and HQ with a maximum lag length of 10 .

The test results for different systems of interest in the context of our analysis are reported in Table 2. The first system considered consists of the long-term interest rate $R$ and the inflation rate $\Delta p$. As mentioned earlier, if the 'Fisher effect' holds, the real interest rate should be stationary. In other words, there should be a cointegration relation between $R$ and $\Delta p$ involving only these two variables. Clearly, including only a constant and seasonal dummy variables in the model, there is strong evidence for one cointegration relation. Because the theoretical relation we have in mind is $R-4 \Delta p$, we have also applied unit root tests to this series. The result is reported in Table 1 . The unit root is rejected at a $5 \%$ level and, hence, the theoretical relation is supported.

As discussed in Sec. 2, we expect to find a money demand relation in a system consisting of $m-p, y, R$, and $\Delta p$. Because we have discovered one cointegration relation between $R$ and $\Delta p$ already, we expect to find two cointegration relations in the four variable set. As can be seen in the lower panel of Table 2, only one such relation is found if the level shifts in $m-p$ and $y$ are ignored, whereas there is some evidence for a cointegrating rank of two if the shift dummy $S 90 q 3$ is included in the system. Even in that case the S\&L test clearly rejects rank 1 only if the lag order recommended by the more parsimonious criterion HQ is used $(n(\mathrm{HQ})=0)$. For this system AIC finds the order $n=4$ which may result in a power reduction of the tests because it is known that LR type tests for the cointegrating rank suffer a power loss if the lag order is specified too large (see, e.g., Lütkepohl \& Saikkonen (1999)).

If there is a cointegration relation involving all four variables of our system in addition to the Fisher relation $R-4 \Delta p$, then it is easy to see that the set of two cointegration relations can be transformed in such a way that one of them involves the three variables $m-p, y$, and $R$ only and the other one includes $R$ and $\Delta p$. Therefore we have also checked the possibility of a cointegration relation between $m-p, y$, and $R$ and found evidence for it if the shift dummy is included. Again clear evidence for a cointegrating rank one in this system is found only if the shorter lag length suggested by the HQ criterion is used. Thus the result for the three variable set is fully consistent with the one obtained for the four variable model. 
Table 2: Cointegration Tests for Sample Period 1975(1) to 1998(4)

\begin{tabular}{|c|c|c|c|c|c|c|}
\hline & deterministic & $H_{0}$ & Johansen & trace test & S\&I & test \\
\hline variables & terms & rank & $n(\mathrm{AIC})$ & $n(\mathrm{HQ})$ & $n(\mathrm{AIC})$ & $n(\mathrm{HQ})$ \\
\hline$\overline{\Delta p_{t}, R_{t}}$ & $c, s d$ & 0 & $18.44^{(*)}$ & "66.82** & $14.45^{*}$ & $42.51^{* *}$ \\
\hline & & 1 & 3.39 & 2.35 & 0.10 & 0.00 \\
\hline & & & {$[n=3]$} & {$[n=0]$} & {$[n=3]$} & {$[n=0]$} \\
\hline$(m-p)_{t}, y_{t}, R_{t}$ & $c, t, s d$ & 0 & 24.69 & 25.36 & 14.11 & 16.23 \\
\hline & & 1 & 8.38 & 7.69 & 6.68 & 6.76 \\
\hline & & 2 & 2.94 & 3.09 & 2.19 & 2.50 \\
\hline & & & {$[n=1]$} & {$[n=0]$} & {$[n=1]$} & {$[n=0]$} \\
\hline & $c, t, s d, S 90 q 3$ & 0 & & & 25.86 & $38.36^{* *}$ \\
\hline & & 1 & & & 6.18 & 9.07 \\
\hline & & 2 & & & 0.02 & 0.00 \\
\hline & & & & & {$[n=1]$} & {$[n=0]$} \\
\hline$(m-p)_{t}, y_{t}, \Delta p_{t}$ & $c, t, s d$ & 0 & 26.64 & $84.99^{* *}$ & 18.48 & $70.30^{* *}$ \\
\hline & & 1 & 14.24 & 15.49 & 9.74 & 6.45 \\
\hline & & 2 & 4.99 & 2.87 & 4.81 & 1.90 \\
\hline & & & {$[n=4]$} & {$[n=1]$} & {$[n=4]$} & {$[n=1]$} \\
\hline & $c, t, s d, S 90 q 3$ & 0 & & & 20.85 & $45.00^{* *}$ \\
\hline & & 1 & & & 5.69 & 4.81 \\
\hline & & 2 & & & 1.66 & 0.99 \\
\hline & & & & & {$[n=4]$} & {$[n=1]$} \\
\hline$(m-p)_{t}, y_{t}, R_{t}, \Delta p_{t}$ & $c, t, s d$ & 0 & $96.51^{* *}$ & $113.89^{* *}$ & $84.96^{* *}$ & $79.13^{* *}$ \\
\hline & & 1 & 23.76 & 26.14 & 13.34 & 15.85 \\
\hline & & 2 & 8.40 & 7.52 & 6.96 & 6.85 \\
\hline & & 3 & 2.89 & 3.06 & 2.05 & 2.65 \\
\hline & & & {$[n=1]$} & {$[n=0]$} & {$[n=1]$} & {$[n=0]$} \\
\hline & $c, t, s d, S 90 q 3$ & 0 & & & 40.55 & $99.56^{* *}$ \\
\hline & & 1 & & & 14.81 & $39.86^{* *}$ \\
\hline & & 2 & & & 6.48 & 9.10 \\
\hline & & 3 & & & 2.11 & 0.00 \\
\hline & & & & & {$[n=4]$} & {$[n=0]$} \\
\hline
\end{tabular}

Notes: $c$ - constant, $t$ - linear time trend, $s d$ - seasonal dummies, $S 90 q 3$ - shift dummy which is 1 from 1990(3) onwards.

$n$ (AIC) and $n$ (HQ) indicate that the lag orders are chosen by the AIC and HQ criterion, respectively, with maximum lag order 10. The actual orders are given in brackets underneath the test values. Asterisks $\left.{ }^{*}\right),{ }^{*}$ and ${ }^{* *}$ indicate that the null hypothesis can be rejected at the $10 \%, 5 \%$ and $1 \%$ levels, respectively, based on critical values from Johansen (1995) for the Johansen trace tests and from Lütkepohl \& Saikkonen (2000) for the S\&L tests. 
By an analogous argument we also expect to find a cointegration relation in a system consisting of $m-p, y$, and $\Delta p$. We have checked that possibility as well and show the test results also in Table 2 . In this case there is even some evidence for a cointegration relation if the GMU shift is not accounted for. Thus, the shift dummy may not be necessary in the present cointegration relation. Notice, however, that including the shift dummy in the deterministic term of the general model (3.1) does not mean that it necessarily enters the cointegration relation in the VECM for $z_{t}$. Therefore we base the following analysis on a model with two cointegration relations none of which contains a shift dummy.

These two cointegration relations are the real interest rate $R_{t}^{r}=R_{t}-4 \Delta p_{t}$ and a 'money demand relation' based on money, income and the inflation rate. The latter cointegration relation was estimated by reduced rank regression based on a model including $m-p, y$ and $\Delta p$ with lag order $n=2$, cointegrating rank 1, a constant, centered seasonal dummies, and the three impulse dummies, $I 90 q 3_{t}, I 92 q 4_{t}$, and $I 94 q 4_{t}$ which we have justified in the previous section. Notice that the shift dummy enters the model in differenced form only, that is, we include $I 90 q 3=\Delta S 90 q 3$ instead of $S 90 q 3$. The resulting long-run relation turned out to be

$$
(m-p)_{t}=1.29 y_{t}-11.66 \Delta p_{t}+e c_{t}
$$

This relation will be used in the following more detailed analysis of the individual equations of the system of interest. It differs from the long-run money demand relation used in LW in important respects. Because LW use a stationary interest rate spread variable their long-run relation also includes the three variables entering (3.3). In addition, they include a shift dummy, however, to account for the GMU break. Their income elasticity is one, whereas our elasticity in (3.3) is larger than one. An income elasticity greater than one was also found, for instance, in studies by Issing \& Tödter (1995) and Scharnagl (1998) using different specifications, variables and sample periods. They argue that it reflects a decline in the velocity of money. Interestingly, the DBB has actually assumed a declining velocity in specifying the preannounced growth rate for the money stock since the late 1980s (see Baltensperger (1998, p. 504)). Therefore the relation in (3.3) is quite plausible. Moreover, because we now use the full historically available data set for the era of monetary targeting, the insignificance of the GMU shift in the cointegrating relation may indicate that the postGMU adjustments of $y$ and $m-p$ have stabilized. The fact that the break cancels in the 
cointegration relation represents a special form of co-breaking in econometric terminology (Hendry \& Mizon (1998)).

In the next section we discuss the individual equations of our final structural VECM model which also includes the unmodeled variables.

\section{The Empirical Model}

The modeling approach is similar to that used by LW, that is, we include four lags of all variables and add the two cointegration relations as additional variables in the system. Then we reduce the model by sequentially eliminating insignificant variables ( $t$-ratios smaller than $2)$. The reduction procedure is not based on the full system but on single equations. We have used the identifying constraint that the inflation rate is the only variable that enters in unlagged form and it only enters in the money equation in this way. Thereby we effectively consider a recursive system at the specification stage. The resulting estimates of the single equations are reported and discussed in the following.*

The estimated money demand equation is ( $t$-values in parentheses)

$$
\begin{aligned}
& \Delta(m-p)_{t}=\underset{(-6.3)}{-0.154 e c_{t-1}-} \underset{(-3.3)}{.206} R_{t-1}^{r}
\end{aligned}
$$

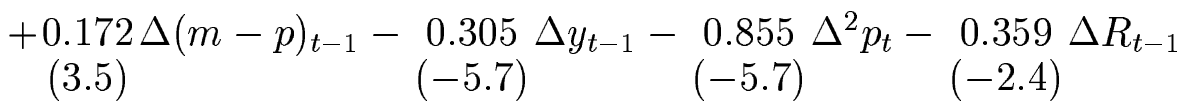

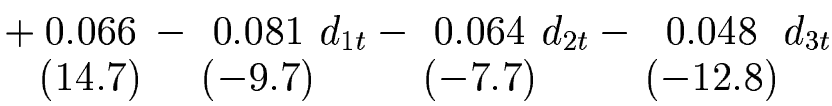

$$
\begin{aligned}
& +0.139 I 90 q 3_{t}-0.026 I 92 q 4_{t}-0.028 I 94 q 4_{t}+\hat{u}_{m t} \\
& \begin{array}{lll}
(18.9) \quad(-3.6) \quad(-3.8)
\end{array} \\
& T=92[1976(1)-1998(4)] \\
& \bar{R}^{2}=0.91, \mathrm{SE}=0.0069 \quad \mathrm{JB}=2.40(0.30) \quad \operatorname{RESET}(1)=0.32(0.58) \\
& \operatorname{LM}(2)=1.58(0.21) \quad \operatorname{LM}(4)=0.83(0.51) \quad \operatorname{LM}(8)=1.33(0.24) \\
& \operatorname{ARCH}(1)=0.86(0.36) \quad \operatorname{ARCH}(2)=0.46(0.64) \quad \operatorname{ARCH}(4)=0.59(0.67)
\end{aligned}
$$

Here JB refers to the Jarque-Bera test for nonnormality, RESET is the usual test for general nonlinearity and misspecification, $\operatorname{LM}(k)$ denotes a Lagrange multiplier (LM) test for

${ }^{*}$ The computations reported in this section were done by EVIEWS 3.1. 
$k$-th order residual autocorrelation, $\operatorname{ARCH}(k)$ is an LM test for $k$-th order autoregressive conditional heteroscedasticity and values in parentheses behind the test statistics are the corresponding $p$-values. Given the foregoing results, the residuals appear to be normally distributed as well as free of autocorrelation and autoregressive conditional heteroscedasticity. Furthermore, the RESET test indicates that no obvious nonlinearity is present. The negative coefficient of the long-run relation $e c_{t-1}$ implies that excess money lowers money growth, as one would expect in a stable model. Moreover, the negative coefficient of the real interest rate $R_{t-1}^{r}$ indicates that high real long-term interest rates and hence high opportunity costs for holding money decrease real money balances.

The income equation was estimated as

$$
\begin{aligned}
& \Delta y_{t}=0.057 e c_{t-1} \\
& +0.263 \Delta(m-p)_{t-1}+0.166 \Delta(m-p)_{t-2}-0.288 \Delta y_{t-1}+0.230 \Delta y_{t-4} \\
& \text { (3.1) } \\
& (-3.2)
\end{aligned}
$$

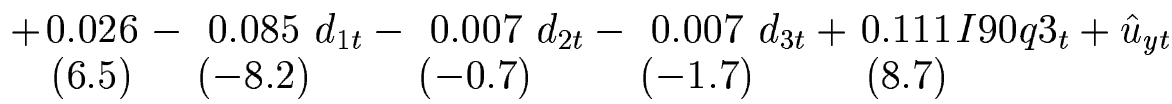

$$
\begin{aligned}
& T=92[1976(1)-1998(4)] \\
& \bar{R}^{2}=0.92, \mathrm{SE}=0.0122 \quad \mathrm{JB}=1.83(0.40) \quad \operatorname{RESET}(1)=0.02(0.88) \\
& \operatorname{LM}(2)=1.80(0.17) \quad \operatorname{LM}(4)=1.96(0.11) \quad \operatorname{LM}(8)=1.31(0.25) \\
& \operatorname{ARCH}(1)=0.70(0.40) \quad \operatorname{ARCH}(2)=0.50(0.61) \quad \operatorname{ARCH}(4)=0.43(0.79)
\end{aligned}
$$

Again the diagnostics do not indicate any problems with autocorrelation, conditional heteroscedasticity, nonnormality or nonlinearity. The income equation includes the error correction term $e c_{t-1}$ with the expected positive sign so that excess money stimulates growth in real income. Clearly, there is dynamic feedback between income and money with lags of both variables appearing in both equations. The deterministic terms are the same as in the money equation except for the impulse dummies $I 92 q 4_{t}$ and $I 94 q 4_{t}$ which are not needed in the income equation. 
The inflation equation was found to be

$$
\begin{aligned}
& \Delta^{2} p_{t}=0.122 \Delta(m-p)_{t-3}+0.093 \Delta y_{t-4} \\
& \begin{array}{ccc}
1.019 \Delta^{2} p_{t-1}-\underset{(-10.4)}{0.978} \Delta^{2} p_{t-2}-0.719 \Delta^{2} p_{t-3}-0.214 \Delta^{2} p_{t-4} \\
(-8.6) & (-6.4) & (-2.2)
\end{array} \\
& +0.067 \Delta p m_{t-4}
\end{aligned}
$$

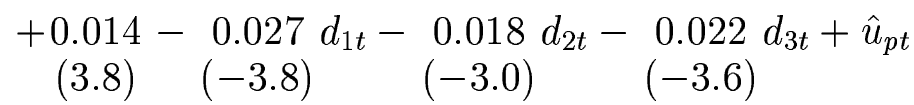

$$
\begin{aligned}
& T=92[1976(1)-1998(4)] \\
& \bar{R}^{2}=0.98, \mathrm{SE}=0.0047 \quad \mathrm{JB}=0.79(0.67) \quad \operatorname{RESET}(1)=0.02(0.89) \\
& \operatorname{LM}(2)=0.13(0.88) \quad \operatorname{LM}(4)=0.75(0.56) \quad \operatorname{LM}(8)=0.54(0.82) \\
& \mathrm{ARCH}(1)=1.10(0.30) \quad \operatorname{ARCH}(2)=2.51(0.09) \quad \operatorname{ARCH}(4)=1.37(0.25)
\end{aligned}
$$

The diagnostic tests do not indicate any specification problems for this equation either. In addition to the own lags, the estimated equation also includes lags of income and money. Thus, there is obviously considerable interaction between inflation, money and income, as one would expect. However, the error correction term from the money market was not needed to obtain a well-specified equation. Given that we have used unadjusted seasonal data the importance of the seasonal lags in the foregoing equations is not surprising. Moreover, as expected, the import prices have an impact on German inflation which has a delay of one year (four quarters), however. In this case the deterministic terms consist of an intercept and seasonal dummies only. The impulse dummy for the GMU period is not needed here because there is no shift in the inflation rate due to the GMU (see Fig. 1).

Equation (4.3) updates the inflation equation of LW. Because in our present system the real long-term interest rate appears as a second cointegration relation, we also performed a specification search which includes this variable as well. Thereby we found an alternative 
inflation equation with largely satisfactory diagnostics. It is of the form

$$
\begin{aligned}
& \Delta^{2} p_{t}=0.120 R_{t-1}^{r} \\
& +0.117 \Delta(m-p)_{t-3}+0.085 \Delta y_{t-4} \\
& \begin{array}{c}
-0.542 \Delta^{2} p_{t-1}- \\
(-4.0)
\end{array} \underset{(-5.4)}{0.617} \Delta^{2} p_{t-2}-0.468 \Delta^{2} p_{t-3} \\
& +0.008-0.021 d_{1 t}-0.018 d_{2 t}-0.022 d_{3 t}+0.014 I 91 q 4_{t}+\hat{u}_{p t} \\
& \begin{array}{llll}
(2.1) \quad(-3.2) \quad(-3.4) \quad(-3.8) \quad(2.9)
\end{array}
\end{aligned}
$$

$$
\begin{array}{lll}
T=92[1976(1)-1998(4)] & & \\
\bar{R}^{2}=0.98, \mathrm{SE}=0.0044 & \mathrm{JB}=1.60(0.45) & \operatorname{RESET}(1)=0.45(0.51) \\
\operatorname{LM}(2)=0.34(0.71) & \operatorname{LM}(4)=0.48(0.75) & \operatorname{LM}(8)=0.48(0.87) \\
\operatorname{ARCH}(1)=0.71(0.40) & \operatorname{ARCH}(2)=2.17(0.12) & \operatorname{ARCH}(4)=3.96(0.01)
\end{array}
$$

In this equation the import price inflation is not needed anymore. Clearly, the $t$-ratio of $R_{t-1}^{r}$ indicates a significant coefficient estimator. The present equation has a slightly smaller residual standard error than the competing equation (4.3)..$^{\dagger}$ On the other hand, equation (4.4) suffers from significant higher order ARCH effects. The main reason why we do not use it in the following analysis is that a dynamic multiplier analysis as discussed in Section 5 results in the typical price puzzle which means that the inflation rate reacts positively to an increase in the instrument variable $r$. Similar results have been found by Brüggemann \& Wolters (1998) in a M1 system for Germany if one does not control for international price movements. It seems that a relevant part of the variation in the inflation rate represents disturbances that stem from international price movements. Therefore, because the overall system has satisfactory diagnostics and impulse responses when using the inflation equation (4.3), we prefer that equation in our subsequent analysis.

\footnotetext{
${ }^{\dagger}$ If we exclude the dummy variable $I 91 q 4_{t}$ the standard error increases to $\mathrm{SE}=0.0046$.
} 
Our estimated equation for the long-term interest rate is

$$
\begin{aligned}
& \begin{aligned}
\Delta R_{t}=- & 0.039 R_{t-1}^{r} \\
& (-2.2)
\end{aligned}
\end{aligned}
$$

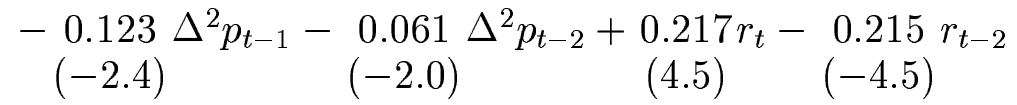

$$
\begin{aligned}
& +0.001+\hat{u}_{R t} \\
& \text { (0.7) } \\
& T=92[1976(1)-1998(4)] \\
& \bar{R}^{2}=0.19, \mathrm{SE}=0.0048 \quad \mathrm{JB}=0.43(0.81) \quad \operatorname{RESET}(1)=0.82(0.37) \\
& \operatorname{LM}(2)=0.41(0.66) \quad \operatorname{LM}(4)=1.52(0.21) \quad \operatorname{LM}(8)=1.21(0.30) \\
& \operatorname{ARCH}(1)=2.09(0.15) \quad \operatorname{ARCH}(2)=1.36(0.26) \quad \operatorname{ARCH}(4)=0.91(0.46)
\end{aligned}
$$

These estimates are in line with the Fisher real interest rate hypothesis in which it is assumed that inflation drives nominal interest rates. This means that the nominal interest rate adjusts to real rates. Again the diagnostic tests do not indicate specification problems. Although our unit root tests indicated that $r$ is $I(0)$ we find here that only the differences of this variable may actually be needed in (4.5). This may be a hint that $r$ almost behaves like an $I(1)$ variable.

The equation for the instrument variable $r$ turned out to contain own lags only. Thereby our decision to condition on this variable is supported. We found the following autoregressive model for this variable:

$$
\begin{aligned}
& r_{t}=\begin{array}{l}
1.205 \\
(19.9)
\end{array} r_{t-1}-0.271 r_{t-3}+0.004+\hat{u}_{r t} \\
& T=92[1976(1)-1998(4)] \\
& \bar{R}^{2}=0.94, \mathrm{SE}=0.0062 \quad \mathrm{JB}=325.98(0.00) \quad \operatorname{RESET}(1)=2.16(0.15) \\
& \operatorname{LM}(2)=0.98(0.38) \quad \operatorname{LM}(4)=1.08(0.37) \quad \operatorname{LM}(8)=1.13(0.35) \\
& \operatorname{ARCH}(1)=0.003(0.96) \quad \operatorname{ARCH}(2)=0.07(0.93) \quad \operatorname{ARCH}(4)=0.56(0.69)
\end{aligned}
$$

As is often the case for financial data, the residuals show significant deviations from normality. On the other hand, they pass all other tests. Because the normality is only of limited importance in our analysis and we condition on $r$, we do not regard this result as problematic. 
We also performed CUSUM and CUSUM-of-squares tests for all the equations and found no indication of model instability.

So far we have considered the equations of our system individually. Such a modeling strategy is justified if it results in a system without instantaneous correlation between the residuals. The residual correlation matrix from the single equation estimations of (4.1), (4.2), (4.3) and (4.5) is

$$
\hat{R}=\left[\begin{array}{rrrr}
1.00 & -0.01 & -0.02 & 0.18 \\
-0.01 & 1.00 & 0.02 & 0.15 \\
-0.02 & 0.02 & 1.00 & -0.24 \\
0.18 & 0.15 & -0.24 & 1.00
\end{array}\right] \begin{gathered}
\Delta(m-p) \\
\Delta y \\
\Delta^{2} p \\
\Delta R
\end{gathered}
$$

Clearly, all off-diagonal elements are relatively small and the actual correlations may well be zero and, thus, we may have a recursive system. The largest correlation in absolute value is 0.24 . Despite the small correlation between the residuals we have estimated our system with three-stage least squares (3SLS). The estimates are given in Table 3. Comparing the estimates in the table to the single equation estimates it is obvious that they are quite similar, as expected in the case of an almost diagonal residual covariance matrix.

In our preferred model the only instantaneous endogenous variable entering the righthand side is $\Delta^{2} p$ in the money equation. Thus, most of the interaction between the variables enters in a dynamic way through the lags of the endogenous variables. The error correction term for money is significant in the money demand and the output equations. Excess money reduces the growth in real money whereas it has a positive effect on output growth. The real long-term interest rate influences money growth and the long-term interest rate in a negative way. This leads to a feedback relation between money and output in the long-run cointegration relations whereas inflation is unidirectional causal for money, output and the long-term interest rate.

There is also considerable interaction in the short-run part of our VECM. For instance, lagged money growth affects inflation and output growth but not the long-term interest rate directly. Lagged inflation influences only the long-term interest rate. Short-run feedback relations exist between money and output growth. Moreover, the long-term interest rate has a direct lagged influence on real money growth. The instrument variable $r$ enters the system via its impact on the long-term interest rate. 
Table 3: 3SLS Estimates of M3 System,

Estimation Period 1976(1) - 1998(4)

\begin{tabular}{|c|c|c|c|c|}
\hline & $\Delta(m-p)_{t}$ & $\Delta y_{t}$ & $\Delta^{2} p_{t}$ & $\Delta R_{t}$ \\
\hline$e c_{t-1}$ & $\begin{array}{l}-0.167 \\
(-6.7)\end{array}$ & $\begin{array}{c}0.056 \\
(2.6)\end{array}$ & & \\
\hline$R_{t-1}^{r}$ & $\begin{array}{l}-0.181 \\
(-3.0)\end{array}$ & & & $\begin{array}{l}-0.036 \\
(-2.1)\end{array}$ \\
\hline$\Delta(m-p)_{t-1}$ & $\begin{array}{c}0.167 \\
(3.7)\end{array}$ & $\begin{array}{c}0.256 \\
(3.2)\end{array}$ & & \\
\hline$\Delta(m-p)_{t-2}$ & & $\begin{array}{c}0.180 \\
(2.7)\end{array}$ & & \\
\hline$\Delta(m-p)_{t-3}$ & & & $\begin{array}{c}0.128 \\
(4.9)\end{array}$ & \\
\hline$\Delta y_{t-1}$ & $\begin{array}{c}-0.317 \\
(-6.3)\end{array}$ & $\begin{array}{c}-0.286 \\
(-3.4)\end{array}$ & & \\
\hline$\Delta y_{t-4}$ & & $\begin{array}{c}0.225 \\
(3.2)\end{array}$ & $\begin{array}{c}0.100 \\
(3.7)\end{array}$ & \\
\hline$\Delta^{2} p_{t}$ & $\begin{array}{c}-1.083 \\
(-4.9)\end{array}$ & & & \\
\hline$\Delta^{2} p_{t-1}$ & & & $\begin{array}{l}-1.027 \\
(-11.5)\end{array}$ & $\begin{array}{c}-0.114 \\
(-2.3)\end{array}$ \\
\hline$\Delta^{2} p_{t-2}$ & & & $\begin{array}{c}-0.992 \\
(-9.6)\end{array}$ & $\begin{array}{c}-0.057 \\
(-1.9)\end{array}$ \\
\hline$\Delta^{2} p_{t-3}$ & & & $\begin{array}{c}-0.731 \\
(-7.1)\end{array}$ & \\
\hline$\Delta^{2} p_{t-4}$ & & & $\begin{array}{c}-0.216 \\
(-2.5)\end{array}$ & \\
\hline$\Delta R_{t-1}$ & $\begin{array}{c}-0.349 \\
(-2.5)\end{array}$ & & & \\
\hline$r_{t}$ & & & & $\begin{array}{c}0.237 \\
(5.4)\end{array}$ \\
\hline$r_{t-2}$ & & & & $\begin{array}{c}-0.227 \\
(-5.1)\end{array}$ \\
\hline$\Delta p m_{t-4}$ & & & $\begin{array}{l}0.070 \\
(2.7)\end{array}$ & \\
\hline
\end{tabular}

Note: Deterministic terms not shown. 
Given these interactions between the variables it is of interest to analyze the dynamic structure in more detail. In the next section we will perform an impulse response analysis. We will also examine the impact of changes in the instrument variable $r$ to study the transmission process of the DBB's monetary policy.

\section{$5 \quad$ Impulse Response Analysis}

In this section we will consider the effects of impulses hitting the system given in Table 3 . For this purpose we remove all deterministic terms and the 'unmodeled variable' $p m$ from the system and trace the marginal effects of changes in $r$ as well as impulses in the different equations of our model. Removing an unmodeled variable means that it is regarded as fixed in the impulse response analysis. The constancy assumption implies that it is not affected by impulses hitting the system. Such an assumption may be justified for a variable like import price inflation.

It has been criticized that in a model with instantaneously correlated residuals, isolated shocks to individual equations may not actually occur in the underlying system. Therefore the model cannot be expected to reflect the responses to such shocks adequately. In our system the estimated instantaneous residual correlations are small, however. Moreover, we are primarily interested in the effects of changes in the policy variable of the DBB. Clearly, the critique does not apply for changes in an exogenous variable. The additional impulse responses are of interest here for checking the plausibility of the estimated relations between the variables of our system. Given that the residual correlation matrix has very small offdiagonal elements, it is not unreasonable to treat it as a diagonal matrix for the purpose of an impulse response analysis.

In our system, the original variables in $z_{t}$ are $(m-p)_{t}, y_{t}, \Delta p_{t}$, and $R_{t}$. Because we are interested in the behaviour of nominal money, we proceed as in LW in computing the impulse responses by setting up an extra equation for $p$. Confidence intervals are based on Hall's bootstrap procedure as proposed by Benkwitz, Lütkepohl \& Wolters (2001) because this procedure has a built-in bias correction in contrast to standard bootstrap confidence intervals. The number of bootstrap replications is 1500. The results are depicted in Figure 2. Notice that the intervals are estimated $95 \%$ confidence intervals for the individual impulse 
The dynamic interactions of the variables are generally as expected. In particular, a permanent increase in the overnight rate $r$ leads to a long-term reduction in nominal money, output, and inflation. Moreover, it drives up the nominal long-term interest rate. Notice, however, the delayed impact on the inflation rate which is due to the exclusion restrictions in our final model. Still, the dynamic responses provide clear evidence that the DBB was able to achieve the desired reactions of the inflation rate and also to control the money supply by varying its instrument variable. Our experiment using a permanent change in $r$ is what is usually referred to as a dynamic multiplier analysis. In Section 3 some evidence was found that the instrument variable $r$ does not have a unit root. Therefore, one may expect that a one-time impulse in $r$ does not lead to a permanent increase in the variable. Thus, in a standard impulse response analysis one would usually not consider a permanent increase in this variable. However, our estimated univariate time series model for this variable has almost a unit root (see equation (4.6)). Therefore, tracing out the effect of a one-time impulse in the residuals of the model for $r$ has a similar effect to considering the dynamic multipliers of a permanent increase as in Figure 2. If the variable is regarded as the instrument variable of the DBB we find it more appealing to consider the dynamic multipliers.

It is also of interest to study the genuine impulse responses of the system to learn more about the transmission process of monetary policy and to check whether the system produces plausible reactions to shocks and is therefore credible as a framework for analyzing the transmission mechanism of monetary policy. In the first column of Figure 2 the responses of an impulse to nominal money are depicted. Clearly, a one-time impulse has a permanent effect on money itself. The positive and partly delayed responses of income and inflation are plausible. The weakly significant positive reaction of the long-term nominal interest rate to a money shock is not in line with the usual liquidity effect of money. It may be due to the increase in the inflation rate, however. Of course, an increase in the money supply is expected to reduce interest rates if no other adjustment processes take place. In our system, however, the inflation is driven up by money shocks and, hence the final impact on the

\footnotetext{
${ }^{\ddagger}$ Computations are based on own GAUSS programs.
} 
nominal interest rate is not clear a priori. Consequently, the increasing long-term interest rate in response to a money impulse is not implausible. The fact that an impulse in nominal money leads to increasing inflation means that using money as an intermediate target was a suitable strategy, as argued by the DBB.

In the second column of Figure 2 it is seen that a one-time impulse in the real income equation has a persistent effect on income. Hence, it also drives up nominal money and leads to some inflation in the long-run. The seasonal pattern in the response function of the inflation rate may be a statistical artefact caused by the strong seasonality of the inflation rate (see Figure 1). Again, given the reactions of the other variables, it is also not surprising to see a weakly significant increase in the long-term interest rate.

An impulse in the inflation equation results in a statistically insignificant initial decline in the money stock which may be a consequence of policy actions by the DBB. In the long-run the nominal money stock adjusts to a change in the price level, however, and, hence, based on the impulse response estimates, $m$ increases due to a positive impulse in the inflation rate. The inflation variable itself reacts again in a seasonal way and there appears to be some persistence in the reaction. There does not appear to be an important effect on real income due to increased inflation whereas the nominal long-term interest rate is clearly driven up, due to the Fisher effect.

Finally, a shock in the nominal long-term interest rate has a fairly persistent effect on the interest rate itself and tends to reduce money balances, income and the inflation rate. Hence, overall the reactions of the variables are plausible in the light of economic theory. They also conform with the assumed interactions which form the basis of the monetary policy conducted by the DBB when it was still in charge of controlling inflation in Germany.

\section{Conclusions}

We have constructed a small model for the monetary sector of the German economy to study the transmission of the monetary policy of the DBB during the period before the Euro was introduced. Our sample period corresponds to the era of monetary targeting by the DBB from 1975 - 1998. Quarterly, seasonally unadjusted data are used. The endogenous variables in our system are money (M3), real income (GNP), an inflation rate based on 
the GNP deflator and a nominal long-term interest rate. The overnight rate is included as the instrument variable of the DBB and import price inflation is treated as an unmodeled variable to account for international influences.

We have found two cointegration relations among the endogenous variables. One of them represents a Fisher relation which means that the real long-term interest rate is stationary. The second cointegration relation can be interpreted as a money demand relation based on the quantity theory. Our model is constructed around these relations and is a structural from in the sense that it involves an instantaneous effect of the inflation rate on the money variable.

We have used a dynamic multiplier/impulse response analysis to study the dynamic interactions in the model. It turns out that the responses of the variables to shocks in the equations are generally quite plausible. In particular, a permanent increase in the instrument interest rate variable tends to reduce inflation and output growth. It is also interesting to note that an unexpected increase in money tends to increase the inflation rate and output growth. These relations are, of course, central for a monetary targeting policy as pursued by the DBB. Generally our model corresponds quite well to the theoretical framework reflected in the arguments of the DBB used in justifying its monetary policy.

\section{Appendix. Variables and Data Sources}

Seasonally unadjusted quarterly data for the period from the first quarter of 1975 to the fourth quarter of 1998 were used for the following variables taken from the given sources. All data refer to West Germany until 1990(2) and to the unified Germany afterwards.

M3: nominal monthly values from Monatsberichte der Deutschen Bundesbank; the quarterly values are the values of the last month of each quarter. The variable $m$ is log M3.

GNP: quarterly real gross national product from Deutsches Institut für Wirtschaftsforschung, Volkswirtschaftliche Gesamtrechnung. The variable $y$ is log GNP.

Price index: GNP deflator $(1991=100)$ from Deutsches Institut für Wirtschaftsforschung, Volkswirtschaftliche Gesamtrechnung. The variable $p$ is the logarithm of the price index. 
Average bond rate (Umlaufsrendite) $(R)$ : monthly values from Monatsberichte der Deutschen Bundesbank; the quarterly value is the value of the last month of each quarter.

Overnight money market rate $(r)$ : monthly values from Monatsberichte der Deutschen Bundesbank; the quarterly value is the value of the last month of each quarter.

Import price index: PM $(1991=100)$ from Deutsches Institut für Wirtschaftsforschung, Volkswirtschaftliche Gesamtrechnung. The variable pm is the logarithm of PM.

The data may be obtained from the internet,

$$
\text { http://wotan.wiwi.hu-berlin.de/oekonometrie/engl/data.html }
$$

\section{References}

Baltensperger, E. (1998), Geldpolitik bei wachsender Integration, in Deutsche Bundesbank (Ed.), Fünfzig Jahre Deutsche Mark: Notenbank und Währung in Deutschland seit 1948, München: C.H. Beck, pp. 475 - 559.

Benkwitz, A., H. Lütkepohl \& J. Wolters (2001), Comparison of Bootstrap Confidence Intervals for Impulse Responses of German Monetary Systems, Macroeconomic Dynamics, 5, 81 - 100 .

Brüggemann, I. (2001), Zum geldpolitischen Übertragungsmechanismus in Deutschland. Eine Analyse im strukturellen Vektorfehlerkorrekturmodell, Aachen: Shaker Verlag.

Brüggemann, I. \& J. Wolters (1998), Money and Prices in Germany: Empirical Results for 1962 to 1996. In: Galata, R. and Küchenhoff, H. (eds.), Econometrics in Theory and Practice, Heidelberg: Physica.

Deutsche Bundesbank (1997), Überprüfung des Geldmengenziels, Monatsbericht August $1997,17-32$.

Deutsche Bundesbank (1998) (Ed.), Fünfzig Jahre Deutsche Mark: Notenbank und Währung in Deutschland seit 1948, München: C.H. Beck.

Hansen, G. \& J.R. Kim (1996), Money and Inflation in Germany: A Cointegration Analysis, Empirical Economics, 21, 601 - 616. 
Hendry, D.F. \& G.E. Mizon (1998), Exogeneity, causality, and co-breaking in economic policy analysis of a small econometric model of money in the UK, Empirical Economics, 23, 267-294.

Hubrich, K. (1998), System Estimation of the German Money Demand - A Long-run Analysis, Empirical Economics, 24, 77 - 99.

Hubrich, K. (2001), Cointegration Analysis in a German Monetary System, Heidelberg: Physica-Verlag.

Issing, O. (1997), Monetary Targeting in Germany: The Stability of Monetary Policy and of the Monetary System, Journal of Monetary Economics, 39, 67-79.

Issing, O. \& K.-H. Tödter (1995), Geldmenge und Preise im vereinten Deutschland, in D. Duwendag (ed.), Neuere Entwicklungen in der Geldtheorie und Währungspolitik, Duncker \& Humblot, Berlin, 97-123.

Johansen, S. (1995), Likelihood Based Inference in Cointegrated Vector Autoregressive Models, Oxford: Oxford University Press.

Juselius, K. (1996), An Empirical Analysis of the Changing Role of the German Bundesbank after 1983, Oxford Bulletin of Economics and Statistics, 58, 791 - 819.

Juselius, K. (1998), Changing Monetary Transmission Mechanisms within the EU, Empirical Economics, 23, 455 - 481.

Lanne, M. \& H. Lütkepohl (2001), Unit Root Tests for Time Series with Level Shifts: A Comparison of Different Proposals, Economics Letters, forthcoming, Discussion Paper No. 5, 2001, SFB 373, Humboldt-Universität zu Berlin, http://sfb.wiwi.hu-berlin.de.

Lanne, M., H. Lütkepohl \& P. Saikkonen (2001), Comparison of unit root tests for time series with level shifts, Journal of Time Series Analysis, forthcoming, Discussion Paper No. 88, 1999, SFB 373, Humboldt-Universität zu Berlin, http://sfb.wiwi.hu-berlin.de.

Lütkepohl, H. (1991), Introduction to Multiple Time Series Analysis, Berlin: SpringerVerlag. 
Lütkepohl, H. \& P. Saikkonen (1999), Order selection in testing for the cointegrating rank of a VAR process, in R. F. Engle \& H. White (eds), Cointegration, Causality, and Forecasting. A Festschrift in Honour of Clive W.J. Granger, Oxford University Press, Oxford, pp. 168-199.

Lütkepohl, H. \& P. Saikkonen (2000), Testing for the cointegrating rank of a VAR process with a time trend, Journal of Econometrics, 95, 177 - 198.

Lütkepohl, H. \& J. Wolters (1998), A money demand system for German M3. Empirical Economics, 23, 371-386.

MacKinnon, J.G. (1991), Critical values for cointegration tests, in R.F. Engle \& C.W.J. Granger (eds.), Long-run Economic Relationships, Oxford: Oxford University Press, $267-276$.

Perron, P. (1989), The great crash, the oil price shock and the unit root hypothesis, Econometrica, 57, 1361 - 1401 .

Perron, P. (1990), Testing for a unit root in a time series with a changing mean, Journal of Business \& Economic Statistics, 8, 153 - 162.

Saikkonen, P. \& H. Lütkepohl (2000a), Testing for the cointegrating rank of a VAR process with structural shifts, Journal of Business \& Economic Statistics, 18, 451 - 464.

Saikkonen, P. \& H. Lütkepohl (2000b), Trend adjustment prior to testing for the cointegrating rank of a vector autoregressive process, Journal of Time Series Analysis, 21, $435-456$.

Scharnagl, M. (1998), The Stability of German Money Demand: Not just a Myth, Empirical Economics, 23, 355 - 370 .

Wolters, J. \& H. Lütkepohl (1997), Die Geldnachfrage für M3: Neue Ergebnisse für das vereinigte Deutschland, ifo Studien, 43, 35-54.

Wolters, J., T. Teräsvirta \& H. Lütkepohl (1998), Modeling the Demand for M3 in the Unified Germany, Review of Economics and Statistics, 80, 399 - 409. 

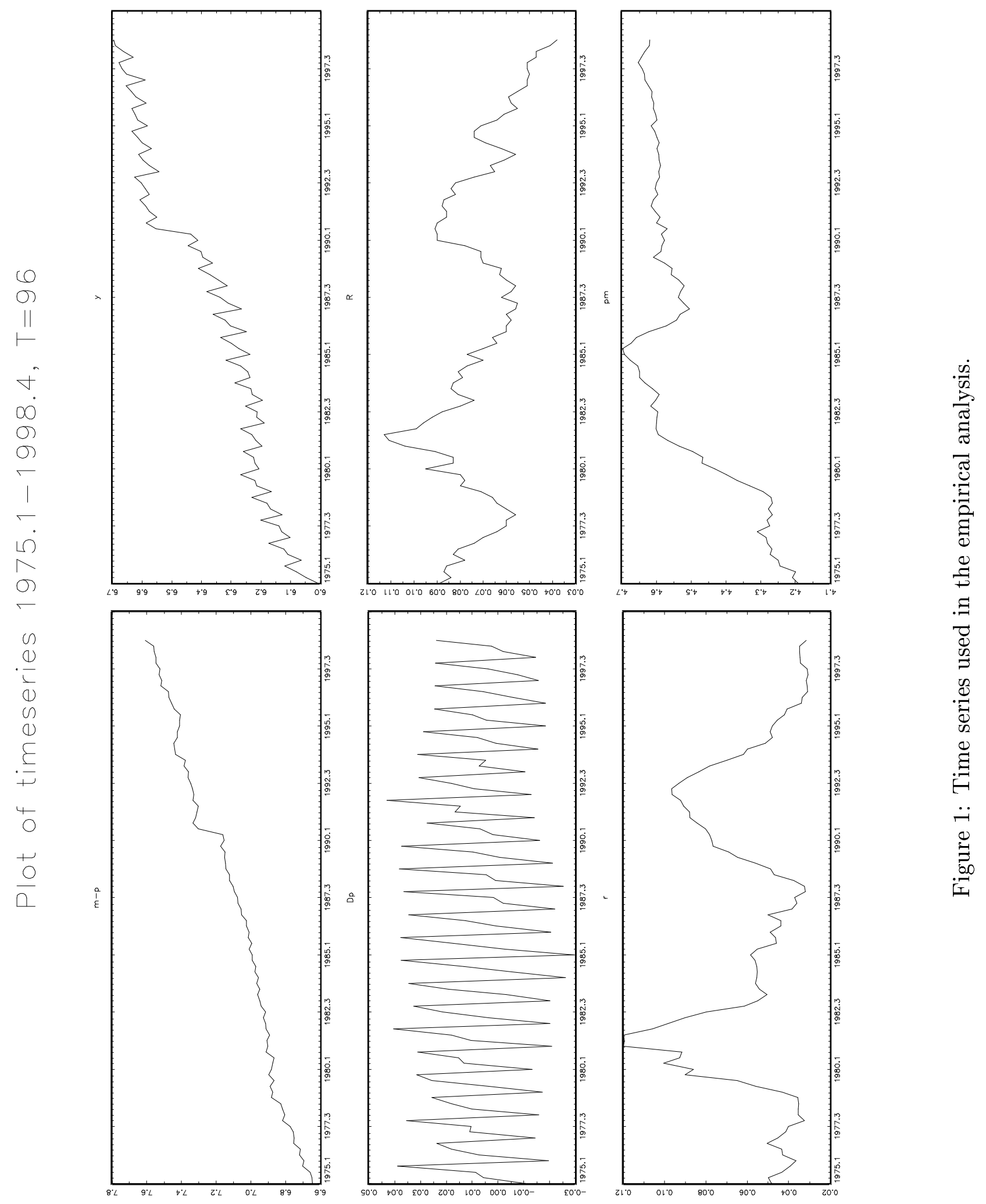

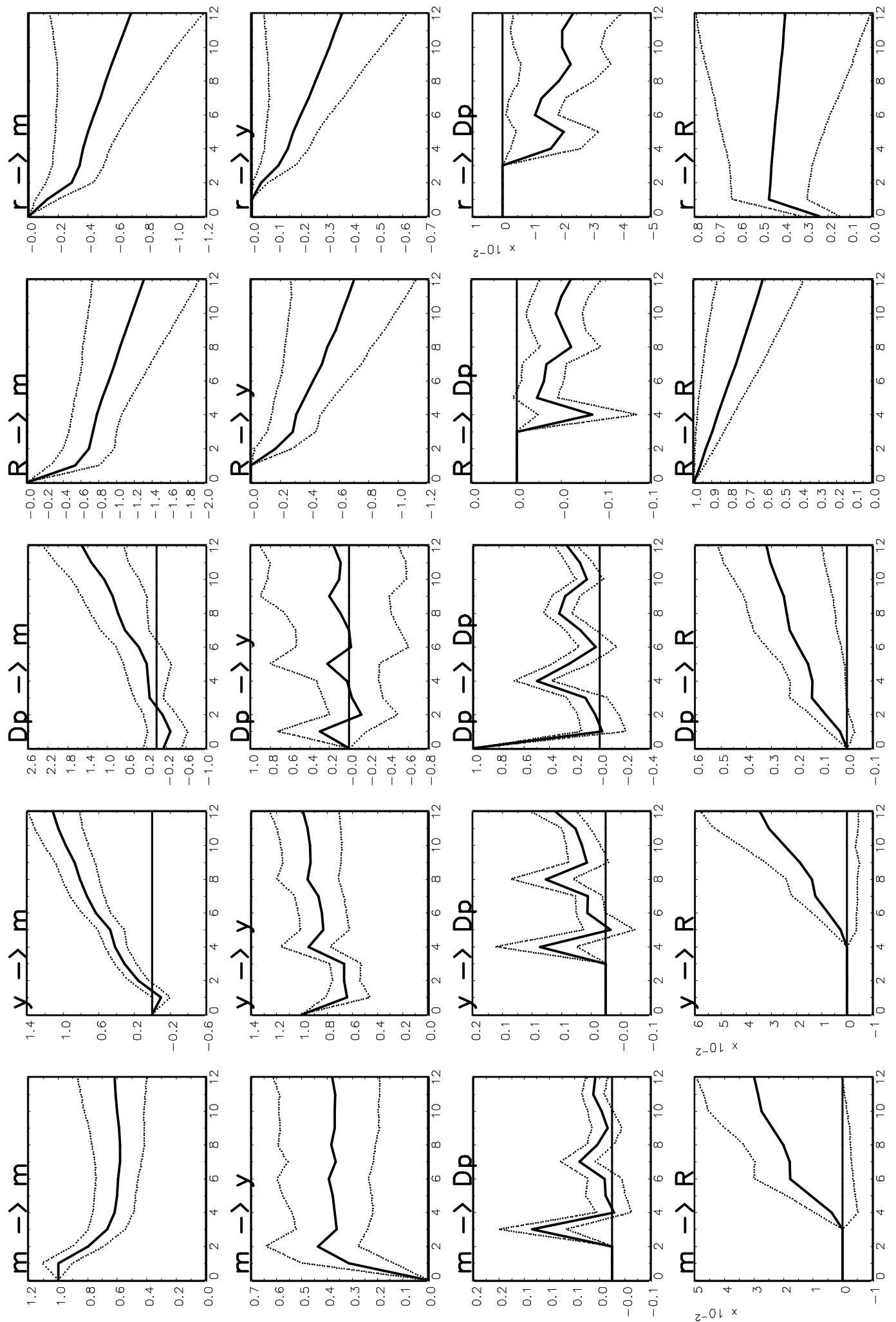

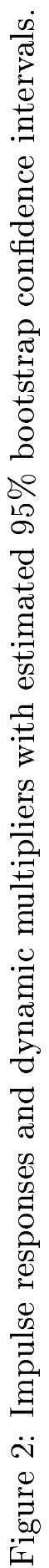

